\title{
DESIGNING AND TESTING A MINI ROBOT FOR TRACKING A WELDING TECHNOLOGICAL PATH
}

\author{
Stelică Timofte, Lenuța Cîndea * \\ Babeș-Bolyai University, Faculty of Engineering \\ Traian Vuia Square, No. 1-4, 320085, Reșița, Romania \\ * Corresponding author. E-mail: lenuta.cindea@ubbcluj.ro
}

\begin{abstract}
In the welding processes of large dimension subassemblies, an advanced mechanism is necessary in order the welding stitch not be interrupted during the change of the operator's position. A tracking model has been designed and tested, for a simple welding path using a mini robot, which can be controlled via mobile phone.
\end{abstract}

Keywords: robot, Arduino, path, testing, validation.

\section{Introduction}

The assembly technological process by welding are found in $90 \%$ of the civil and industrial constructions, automotive and naval industry, and machine building, in one-of-a-kind, series or mass constructions. Sometimes the welding assembly processes are especially complex. Therefore, it is necessary that the transition from the semi-finished to the finished product to be made with the provision of a correct positioning scheme of the semi-finished product subjected to welding. It is recommended to ease the welding processes with the help of some advance mechanisms for semi-manufactured products according to the type of product or the performed procedure [1].

This subject was chosen starting from the idea that in the welding processes of large dimension subassemblies an advance mechanism is necessary so that the welding seam is not interrupted during the change of the operator's position, given the fact that a good quality welding seam is performed only by qualified operators or by the continuity of the process, which is without interrupting the welded seam.

The objective of the paper is to demonstrate that by using a standard app one can control a remote device via Bluetooth. The following facts will be studied: the responses to the commands, their efficiency, their accuracy, the speed, the direction control and if it responds in good time [2].

\section{Arduino Open Source Platform}

Arduino is an open source platform that can be successfully used in the construction of many electronic projects. Arduino platform has become quite popular with people who are beginning to work just with basic electronic and for a good reason, given the fact that it is easier to use than other devices, it does not need a separate piece of hardware (named programmer) in order to add a new code, one can simply use a USB cable [3].

Moreover, the Arduino ID uses a simplified version of $\mathrm{C}++$, thus facilitating the process of learning programming. Arduino was developed at the Ivrea Interaction Design Institute as an easy tool of rapid prototyping designed for students without a background in electronic and programming. As soon as it reached a larger community, the Arduino board began to change in order to adapt to the needs and challenges, differentiating its offer from simple 8 bits boards to products for IoT app, 3D printing and embedded system. All Arduino boards are completely open offering its users the possibility to build them independently and adapt them to their specific needs. The software is also open-source and it is improving through the contribution of the users worldwide [3].

This runs with Mac, Windows and Linux. Teachers and students are using it to develop cheap scientific tools, to demonstrate the principles of chemistry and physics or to start programming and robotics [7].

Designers and architects are building interactive prototypes, musicians and artists are using it for equipment and experimenting new musical instruments. Producers are using it to develop many of the projects shown at Maker Faire, to give an example. Arduino is a key tool for learning new things. Anyone - children, passionate people, artists, programmers - can simply start tinkering following step- by- step instructions of a set or exchanging online ideas with other members of the Arduino community [3].

Although hardware and software designs are available cost-free under copy left licenses, developers have asked that the name Arduino be exclusive for the official product and not be used for derived items without permission. The official document regarding the use of the name Arduino underlines the fact that the 
project is open to incorporating the work of others in the official product [1].

Many products available on the market, compatible with Arduino, have avoided the name of the project by using different names ending in -duino. An early Arduino board with a series interface RS-232 (upper left) and a microcontroller Atmel Atmega8 (black, bottom right); the 14 digital pins I/O are on the upper part, the 6 entry analogic pins on the bottom right and the power connector on the bottom left [1].

\section{Architecture.}

\section{Choosing the Components. Hardware}

Arduino open-source platform is used, based on flexible and easy to use hardware. It consists of a small dimension platform $(68 \mathrm{~mm} / 53 \mathrm{~mm}$ - most common option) developed around a signal processor and it is capable of collecting data from surrounding environment through a series of sensors as well as performing actions on the environment with the use of lights, motors, servomotors and other types of mechanical devices, Fig. 1.

The processor is capable to run a code written in a programming language which is very similar to $\mathrm{C}++$, the specifications of the Arduino developing board are given in Tab.1 [6].

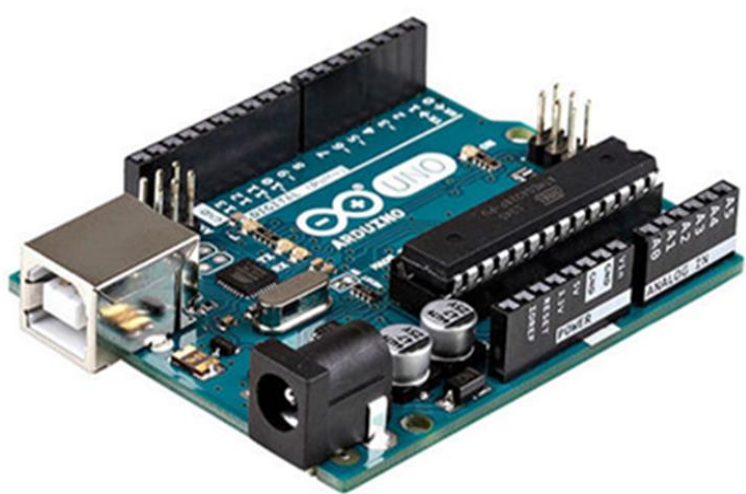

Fig. 1. ARDUINO UNO V3 Board [7]

Tab. 1[7]

\begin{tabular}{|l|l|}
\hline Microcontroller & ATmega328 \\
\hline Working voltage & $5 \mathrm{~V}$ \\
\hline $\begin{array}{l}\text { Imput Voltage } \\
\text { (recommended) }\end{array}$ & $7-12 \mathrm{~V}$ \\
\hline $\begin{array}{l}\text { Imput Voltage } \\
\text { (limit) }\end{array}$ & $6-20 \mathrm{~V}$ \\
\hline Digital pins & 14 (6 PWM output) \\
\hline Analog pins & 6 \\
\hline Output intensity & $40 \mathrm{~mA}$ \\
\hline $\begin{array}{l}\text { Output intensity } \\
3.3 \mathrm{~V}\end{array}$ & $50 \mathrm{~mA}$ \\
\hline
\end{tabular}

\begin{tabular}{|l|l|}
\hline Flash memory & $\begin{array}{l}30 \mathrm{~KB} \\
\text { (ATmega328) } 0.5 \mathrm{~KB} \\
\text { pentru bootloader }\end{array}$ \\
\hline SRAM & $2 \mathrm{~KB}($ ATmega328) \\
\hline EEPROM & $1 \mathrm{~KB}($ ATmega328) \\
\hline Clock speed & $16 \mathrm{MHz}$ \\
\hline
\end{tabular}

The motor driver is based on the integrated L298, being a medium level driver on what conducted power is concerned. This can control motors, which require $2 \mathrm{~A}$ at most. The driver contains a jumper, which enables the Arduino board to charge directly from the power source.

The Bluetooth module $\mathrm{HC}-05$ is a high performance one and requires very little energy. At the same time, its dimensions are small. The product can be used in projects where it is necessary to transfer data easily, within reasonable distances without using a cable.

A phone app is used to transmit entries to the module, which receives and then transfers them to Arduino. In its turn Arduino and the actuators respond accordingly as specified in the source code [7].

In order to detect the distance to an object, a module has been used. This precise module is used for developing a line tracking robot which has infrared line tracking sensors, bottom oriented, as well as a faceoriented sensor, thus enabling it to detect obstacles in its path [4].

The reading of the trajectory of the robot is done with the analogical sensor QTR-1A [8].

Five such sensors that make up the sensorial system of the robot have been used, Fig. 2 .

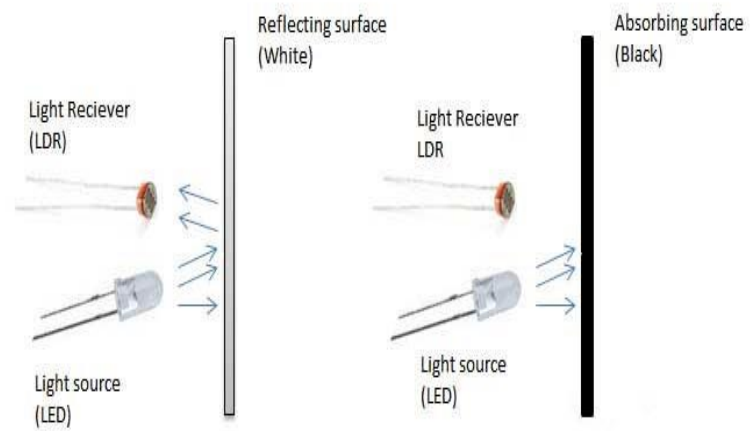

Fig. 2. The two components of the sensor [7]

\section{Designing the Chassis of the Mini Robot}

By using SOLIDWORKS 2016 as designing programme, the chassis of the mini robot has been designed (Fig. 3) and a static and dynamic analysis have been made using the finite element method. By conducting simulations on the 3D model of the chassis, static simulations - one can observe that the chosen material is placed within the stretch category and returns to its initial shape. 
The chassis model has been meshed into finite elements using Mesh for a solid meshing, and it has been fixed in the gripping points of the motors and a force of $100 \mathrm{~N}$ has been applied in the gripping area of the driven wheel in order to conduct the analysis study and simulations on the chassis of the mini robot.

The analysis study has been established with the Run command.

The maximum value of the Stress 1 tension $($ vonMises $)=2134 \mathrm{MPa}$.

This stage of the simulation is part of the results processing and it is at this stage that it was decided, by having analysed the von Mises tensions that the conditions should be static and dynamic [5].

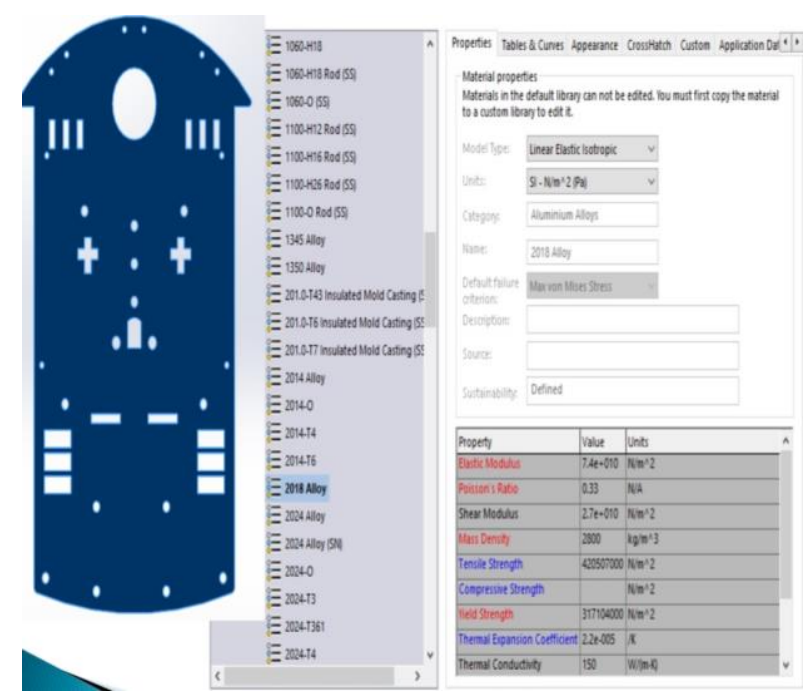

Fig. 3. Choice of the material

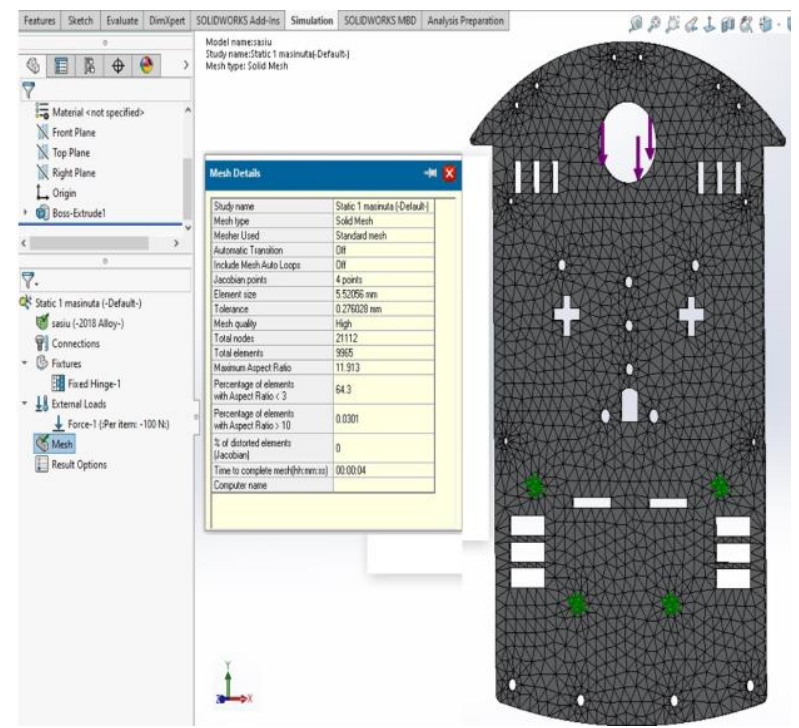

Fig. 4. Meshing in finite elements

Before the processing stage, the program has transferred the border conditions and loads applied on the geometrical elements in the nodes of the meshed model [5].
In the pre-processing stage, analysis studies of the Stress 1 tension have been conducted with a movement display, Fig. 5.

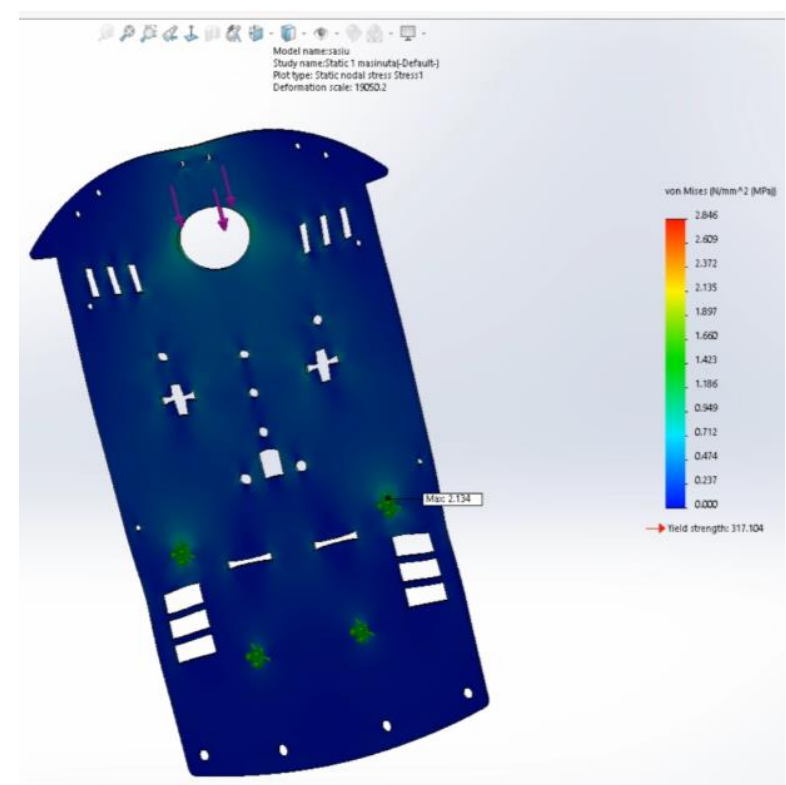

Fig. 5. Stress1 Analyze

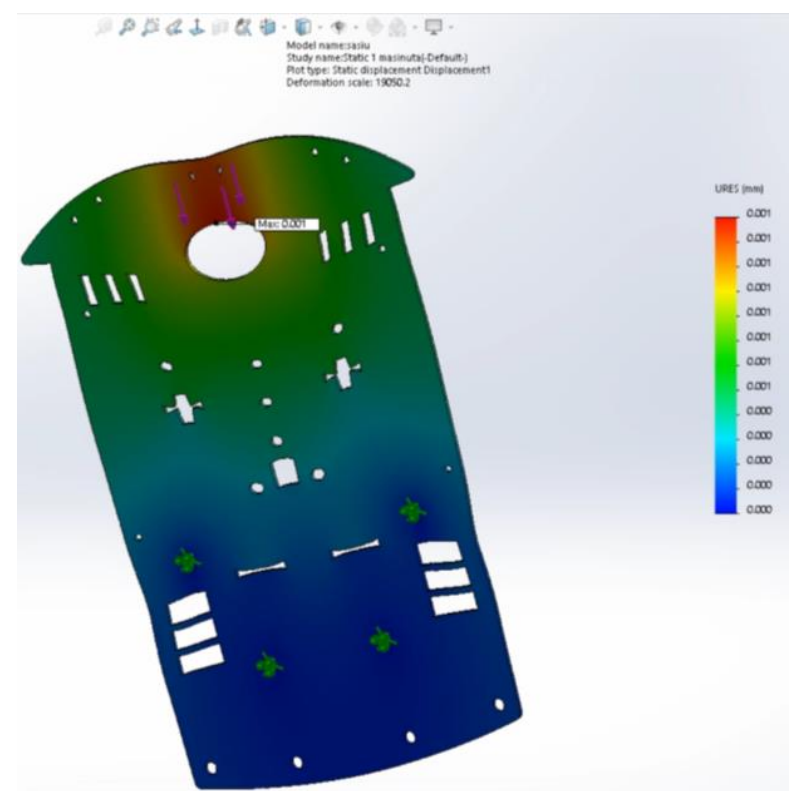

Fig. 6. Simulations with the display of movements

For the next stage, the cutting process, the program code has been established for a batch of 42 pieces for the chassis, on a standard aluminium board.

In Fig. 7, the generating lines for the simulation of the route followed by the laser sawing head are presented. 


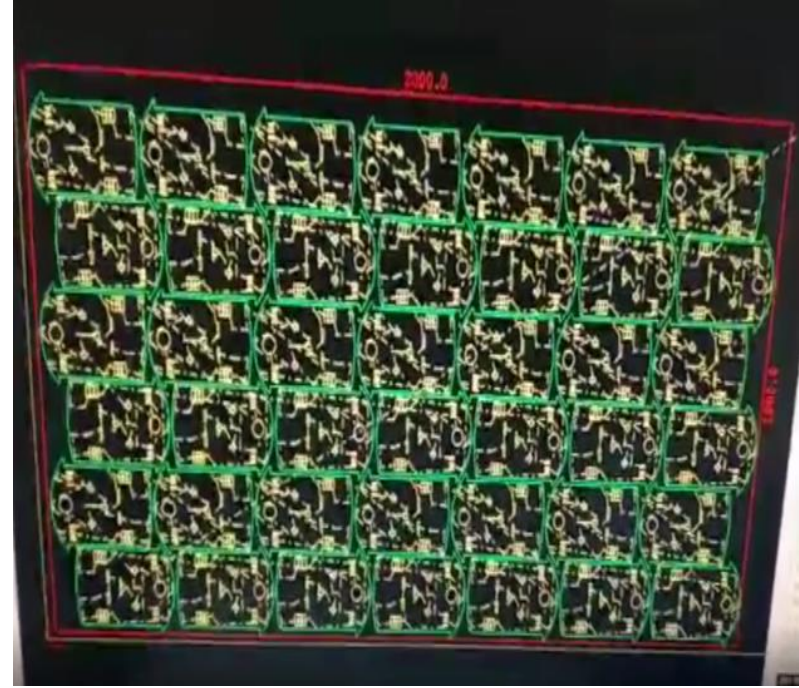

Fig. 7. Simulating the route and generating lines that the laser sawing head must follow in order to cut 42 pieces for the chassis of the mini robot

\section{Testing and Validation of the Mini Robot}

Designing and testing this mini robot had as purpose the finding of solutions for tracking welding paths with more complex configurations by the use of some elements, which ensure the orientation of the welding components in order to track the welding slot on different shaped surfaces [9].

The innovation of the construction is given by the fact that a mobile phone can be used to control the mini robot, which might replace a traditional remote controller, normally used.

The mobile phone has the advantage that it is used most of the time by everyone, thus removing the problem of forgetting the remote controller, or constantly buying new batteries [10].

Another major advantage is the operating Android system, which helped to develop the interface on what control is concerned, given the fact that the Android operating system has a wide range of devices and apps, and new usages are constantly being discovered.

For testing the mini robot, a black line was used instead the welded seam.

Fig. 8 shows the following of the black line by the mini robot.

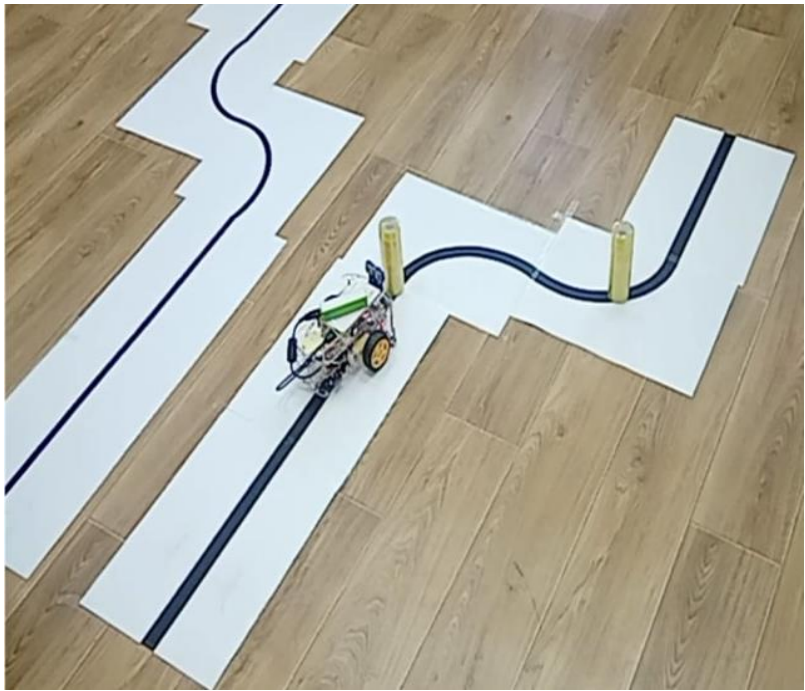

Fig. 8. Testing the mini robot on an established path which simulates the welded seam

\section{Conclusions}

The main objective of this paper has been to control a mini robot onto which an Arduino kit has been installed by using a smartphone.

The project can offer a wide range of future papers and varied applications.

The results of this project are meant to help researchers focus their work on the latest innovations in the domain of mini robots and advanced systems of vehicles by using Arduino and Android technology.

The results may as well be used by car manufacturers in the critical decisions regarding the equipment of the cars with gadgets from the mini robots. This system uses a source code for managing commands based on Android technology and the data transferring via Bluetooth for its operations. In the second part of this project the implementation of the electronic system is underlined and basically, the construction itself.

This system can be a test for all projects and future equipment, which are interested in working with Bluetooth technology and the one offered by Arduino.

In this project, a smartphone and a mini robot have been used, as well as a measure circuit. The possibility of moving the source code onto another developing board is being considered, followed by testing it in a simulator, as well as having more commands on the next board, such as the ones previously mentioned, different sensors, a mobile arm, a vocal system, a video system, etc.

\section{References}

[1] ***: ,Programming Arduino Getting Started with Sketches", McGraw-Hill, 2011.

[2] Monk S.: „Programming Arduino Next Steps: Going Further with Sketches, McGraw Hill Education, 2013. 
[3] ***: ,Arduino FAQ - With David Cuartielles". Malmö University. April 5, 2013.

[4] Ward J. R., Phillips M. J.: "Digitizer Technology: Performance Characteristics and the Effects on the User Interface", IEEE Computer Graphics and Applications. (1987-04-01), Spectrum.ieee.org, 2014.

[5] Cîndea L., Hațiegan C.: "Modelarea și simularea sistemelor mecanice", Editura Eurostampa, 2021.

[6] Lawlis P.K.: "Guidelines for Choosing a Computer Language: Support for the Visionary Organization", http://archive.adaic.com/docs/reports/lawlis/wordexcel/97/gccl.doc.

[7] McRoberts M.: „Beginning Arduino" SpringerVerlag Berlin and Heidelberg GmbH \& Co. KG, 2010.

[8] Gläser T., Jaritz M., Sackl P.: „,Hardware-Hacking: „So baut man einen Tentakel-Roboter", Der Spiegel, 2009.
[9] Stroia M.D., Derbac D., Hațiegan C., Cîndea L.: ,Thermostat model with Arduino uno board for controlling a cooling system,, Annals of the „Constantin Brancusi” University of Targu Jiu, Engineering Series, No. 3/2018.

[10] Schultz, Thomas. „C and the 8051,, (3rd ed.). Otsego, MI: PageFree Publishing Inc, 2004.

\section{Personal Notes}

Mr. Drd. Eng. Timofte Stelică is a PhD student at the Faculty of Engineering of Babeș-Bolyai University.

Ms. Cîndea Lenuța is a university lecturer and has been working in the Faculty of Engineering of Babeș-Bolyai University, since 2005 .

This paper is the research part of Mr. Timofte Stelică's dissertation, materializing with a prototype of a robot that can be ordered via a mobile phone, in several fields of activity.
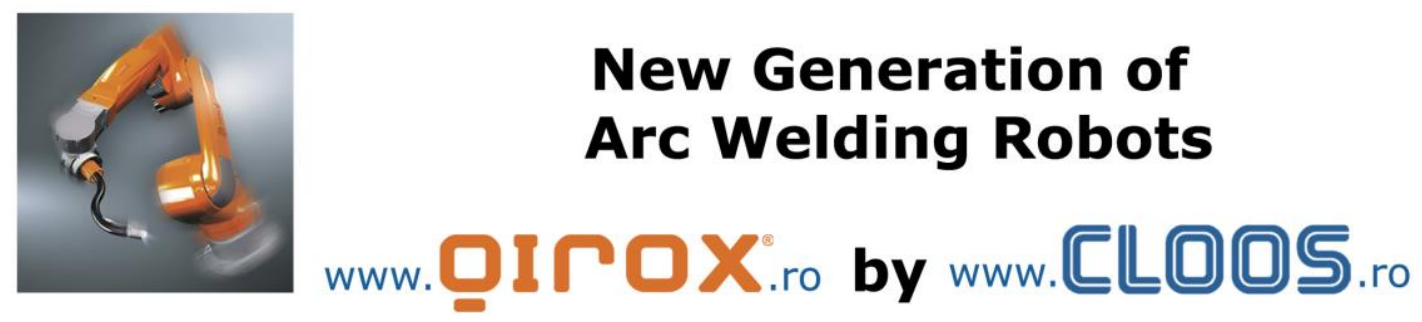